Meta-analysis

\title{
The adverse neuro-developmental effects of postnatal steroids in the preterm infant: a systematic review of RCTs Keith J Barrington*
}

\author{
Address: Royal Victoria Hospital, 687 Pine Ave W. Room C7.68, Montreal, Quebec, H3A 1A1 Canada \\ E-mail: Keith J Barrington* - kbarri@po-box.megill.ca \\ *Corresponding author
}

Published: 27 February 2001

BMC Pediatrics 200 I, I:I

This article is available from: http://www.biomedcentral.com/|47|-243I/I/I

(c) 200 I Barrington, licensee BioMed Central Ltd.
Received: 20 November 2000 Accepted: 27 February 200I

\begin{abstract}
Background: Recent reports have raised concerns that postnatal steroids may cause neurodevelopmental impairment in preterm infants. This systematic review was performed with the objective of determining whether glucocorticoid therapy, to prevent or treat bronchopulmonary dysplasia, impairs neuro-developmental outcomes in preterm infants.
\end{abstract}

Method: A systematic review of the literature was performed. Medline was searched and articles retrieved using predefined criteria. Data from randomized controlled trials with adequate neurodevelopmental follow up (to at least one year) were entered into a meta-analysis to determine the effects of postnatal treatment of preterm infants with glucocorticoids. Cerebral palsy rates, and neuro-developmental impairment (developmental score more than 2SD below the mean, or cerebral palsy or blindness) were analyzed. The studies were divided into 2 groups according to the extent of contamination of the results by treatment of controls with steroids after the initial study period, those with less than 30\% contamination, and those with more than $30 \%$ contamination or size of contamination not reported.

Results: Postnatal steroid therapy is associated with an increase in cerebral palsy and neurodevelopmental impairment. The studies with less contamination show a greater effect of the steroids, consistent with a real direct toxic effect of steroids on the developing central nervous system. The typical relative risk for the development of cerebral palsy derived from studies with less than $30 \%$ contamination is $2.86(95 \% \mathrm{Cl} 1.95,4.19)$. The typical relative risk for the development of neuro-developmental disability among followed up infants from studies with less than $30 \%$ contamination is $1.66(95 \% \mathrm{Cl} 1.26,2.19)$. From this subgroup of studies, the number of premature infants who need to be treated to have one more infant with cerebral palsy (number needed to harm, $\mathrm{NNH}$ ) is 7; to have one more infant with neuro-developmental impairment the $\mathrm{NNH}$ is II.

Conclusions: Postnatal pharmacologic steroid treatment for prevention or treatment of bronchopulmonary dysplasia is associated with dramatic increases in neuro-developmental impairment. As there is no clear evidence in the literature of long term benefit, their use for this indication should be abandoned. 


\section{Introduction}

The history of Neonatology has been a chequered one. Huge, well documented, progressive improvements in neonatal outcomes have been interspersed with multiple setbacks. These disasters have included: an epidemic of retinopathy of prematurity due to unregulated administration of oxygen [1], followed by an increase in cerebral palsy rates when oxygen therapy was too severely restricted [2]; the grey baby syndrome from the use of chloramphenicol when no adequate pharmacokinetic studies had been performed [3]; a gasping syndrome from the use of untested bacteriostatic chemicals in flush solutions [4]; and a neurological syndrome due to bathing infants with hexachlorophene and its unexpected absorption through the skin [5]. All of these disasters have the common underlying cause of introducing therapies into the care of the most fragile of patients without adequate investigation of their potential harm. Despite this history, the postnatal administration of corticosteroids for treatment and prevention of chronic lung disease has become extremely widespread without adequate analysis of long term adverse effects.

The postnatal use of pharmacological doses of corticosteroids came into wide use in neonatal intensive care nurseries following the illustration of short-term improvements in lung mechanics and oxygenation, largely initially as a result of uncontrolled experimentation (for one of which publications I was responsible myself [6]). After many years of further experimentation it has gradually become clear that the only benefit that can be expected from postnatal steroids is an acute improvement in gas exchange and lung mechanics [7]. There does not appear to be any improvement in long-term pulmonary health, as evidenced by the number of babies going home on oxygen or the duration of hospitalization, and there are no adequate long-term pulmonary function studies. The Cochrane systematic review of "moderately early steroids to prevent bronchopulmonary dysplasia" [8] suggests that administration of steroids at 7 to 14 days of age to ventilator and oxygen dependent infants, the postnatal age at which the benefits seem to be greatest, appears to reduce the number of babies who require oxygen at 36 weeks gestation (i.e. a reduction in the rate of diagnosis of BPD). This review also reveals no significant effect on mortality before discharge, the relative risk of death is 0.71 , with $95 \%$ confidence intervals of 0.44 to 1.15. In another systematic review, Doyle and Davis pointed out that the late mortality in one study was not included in the Cochrane review, and were unable to demonstrate an improvement in mortality in any age group [9]. Specifically the relative risk of mortality among the studies with steroids commenced at 7 to 14 days was 0.81 , (event rate difference was $-5 \%$, 95\% CI -11, 1.1) and was not statistically significant.
As noted above, the short term improvements in lung function do not appear to translate into long-term improvement in health outcomes. In contrast to the lack of demonstrated long-term benefit, there have been recent suggestions that the long-term neurodevelopment of babies who have received pharmacological doses of steroids may be substantially impaired, with a major increase in developmental disabilities and movement disorders [10]. There has been a major delay in the detection of this effect as most studies have been unable detect such an effect, even on the rare occasions it has been looked for [11], because of the frequent use of steroids in the control groups of randomized studies, ranging up to a $62 \%$ crossover [12].

In order to more precisely estimate the potential size of the problem I have performed a systematic review of the literature, with the objective of determining whether postnatal administration of pharmacological doses of steroids, to ventilated preterm infants, for prevention or treatment of bronchopulmonary dysplasia, is associated with an increase in neuro-developmental impairment; and of assessing the size of the effect.

\section{Methods}

In order for a trial to be included in this review it had to be a report of a randomized controlled trial of glucocorticoids given for the treatment or prevention of bronchopulmonary dysplasia. The study subjects had to be premature infants, less than 32 weeks gestation. The outcome measure of interest which was required was long term neuro-developmental outcome at 1 year of age or later.

A literature search was performed in February 2000 and last updated on September $25^{\text {th }} 2000$. The medline database was searched using the Pubmed search engine. The search strategy included steroid ${ }^{*}$ or glucocorticoid ${ }^{*}$ and bronchopulmonary dysplasia or chronic lung disease and was limited to humans, newborn infants, and randomized controlled trials. In addition I examined the references of the latest edition of the Cochrane reviews on postnatal steroid use, and other review articles, and searched my personal data files using a similar search strategy. During the preparation of this manuscript a further publication appeared [13]. One of the reviewers of the first version of this manuscript also pointed out 2 further publications, on which had not been found by my first search [14] and a second, which was a letter in the correspondence column of a journal, which included relevant information [15]. I also searched the controlled clinical trials register of the Cochrane database of controlled clinical trials. After obtaining the initial results of the search the abstracts of the articles or the entire article 
was examined to determine whether long term outcomes were reported.

Estimates of relative risk and risk difference were calculated using Metaview version 4.1, and 95\% confidence intervals were used. A fixed effect model was assumed. The trials were subdivided into those that reported that there was no contamination of the original randomization by later treatment of controls with steroids, those with less than 30\% contamination, those with more than 30\% contamination and those with no clear report of the frequency of treatment of controls with steroids. The studies with $\mathrm{o}$ to $30 \%$ contamination were separated according to a pre-planned analysis and used to develop estimates of risk.

\section{Characteristics of the studies}

Eight reports of randomized controlled trials, which included some report of long-term neuro-developmental outcomes, were obtained. Yeh et al investigated a 28 day course of steroids, starting on day 1 in ventilated infants less than $2000 \mathrm{~g}$ birth weight [16]. The initial sample size was 262 infants, and both the randomization and the intervention were masked. 83 infants died during initial hospitalization, and 15 afterward, leaving a potential of 164 survivors to be followed, of these 22 were lost to follow up in a further 9 follow up studies were not completed. This left a total of 133 infants for whom follow up data are presented. Eight of the 70 control infants received open label steroids after the study period (11.4\%); five of the 63 dexamethasone treated infants had further steroids after the study period. At approximately 24 months corrected age $81 \%$ of the surviving infants, $n=133$, had a neuro-developmental examination including analysis of motor disability and application of the Bayley scales of infants development. In this study, steroid use was associated with a $41 \%$ rate of significant handicap (severe neurologic deficit or Bayley PDI and/or MDI less than 70) among 63 dexamethasone treated infants, compared to a $31 \%$ rate among the 70 controls [17]. Follow up assessment was masked to treatment group.

O'Shea et al studied a 42 day tapering course of steroids in 118 very low birth weight infants $(<1501 \mathrm{~g}$ birth weight) who were ventilator dependent at 15 to 25 days and requiring more than $30 \% \mathrm{O}_{2}$. The method of randomization is not clear from the study reports but the medication administration was masked, no crossover of study participants was allowed. Follow up of 93 of the 95 surviving infants was performed at one year corrected age, using the Bayley scales, Vineland adaptive behaviour scales and a neuro-developmental examination. This study showed that cerebral palsy frequency was 12/ 48 steroid treated and 3/45 controls; the rate of neurodevelopmental impairment (cerebral palsy or Bayley
MDI $<68$ or blindness) was 16 out of 50 dexamethasone treated infants and 8 out of 45 controls [10]. Outcome assessment was masked.

Shinwell's data [13], are from follow up of 159 of the infants enrolled in a multicentre trial in Israel [18]. This study investigated 248 ventilated infants weighing less than $2000 \mathrm{~g}$, starting before 12 hours of life, 3 days of dexamethasone or placebo were given. Both group allocation and medication administration appear to have been masked. Thirty of 116 controls (25.8\%) received open label steroids after the study, 26 of the 79 survivors in this group (33\%). 58 infants died during hospitalization and 5 after discharge, 31 infants did not have adequate data from follow up, which was performed at 24 to 71 months corrected age. There was therefore a total of 159 infants, $83.6 \%$ of the survivors, for whom adequate data were available. The study demonstrated that 39 of 80 dexamethasone treated infants and 12 of 79 controls had cerebral palsy, and also that only 36 of 80 dexamethasone treated infants had normal development compared to 56 of 79 control babies. Not all of these infants had formal developmental scoring, however, I have assumed that infants referred to as "severely abnormal development" were neuro-developmentally impaired by my definition. Follow up examination was masked.

The fourth study to satisfy the criteria was the 1989 report of the trial of Cummings et al [19]. In this study 36 infants of less than $1251 \mathrm{~g}$ birth weight who were ventilator and oxygen dependent at 2 weeks of age were randomized to either 42 days, or 18 days of steroids or to control. Randomization and drug administration were both masked; no crossover is mentioned in the report of the study. Follow up assessment was performed at 15 months of age of all of the 23 surviving infants. Nine of the 18 steroid treated infants who were followed up were "normal" (normal neurological examination and Bayley index $>83$ ) and 2 out of 5 controls. This study reported that 5 out of 18 steroid treated and 2 of the five survivors in the control group had either cerebral palsy or severe truncal hypotonia. These results have been entered into the meta-analysis as if all had cerebral palsy.

The collaborative dexamethasone trial group studied 282 very low birth weight infants, of whom 62 infants died. The randomization schedule and the treatment with steroids were both masked. There were 11 infants not followed up to leave a total of 209 for whom there was follow up information. Although rescue treatment with steroids was supposed to be reserved for "life threatening deterioration" this study reported a $43 \%$ contamination rate of treatment of the whole control group with steroids [11], being 40.4\% of the surviving, followed up controls. This European multicentre trial re- 


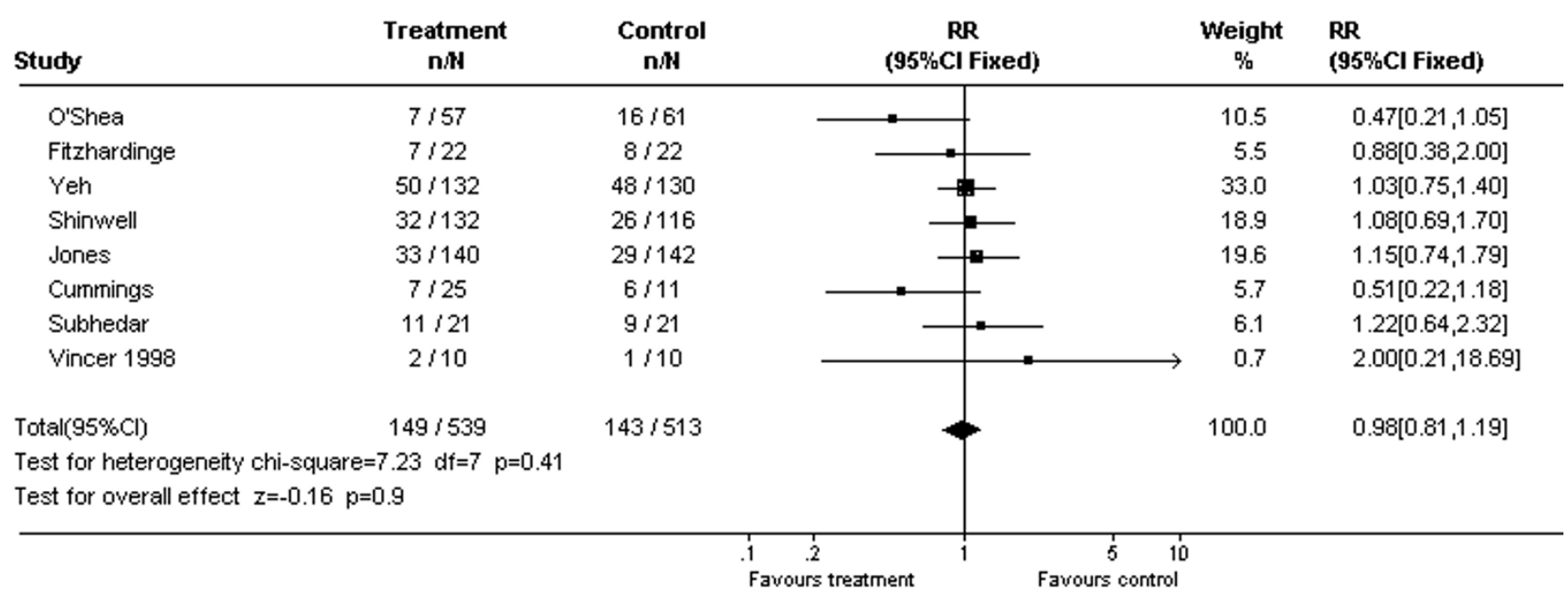

\section{Figure I}

Meta-analysis of the effects of postnatal steroids on death. Studies are displayed in order of the degree of known contamination of the randomization, Fitzhardinge and O'Shea known to have no contamination, Yeh, Shinwell, and Jones with progressively increasing degrees of contamination, and Cummings, Subhedar and Vincer unknown.

ported that 20/100 steroid treated and 18/109 control infants developed cerebral palsy, as assessed at a three year follow up, and that 38/100 steroid treated and 41/ 109 control infants were recognized as being disabled at that time, most of whom probably fit my definition for neuro-developmental impairment. It must be stated that follow up methodology varied among the participating centers, and it is not clear if it was masked.

In 1974 Fitzhardinge et al [14] published neuro-developmental follow up data from 24 survivors of a study which was not initially designed to investigate prevention of bronchopulmonary dysplasia, and therefore was not discovered by my first literature search which included that search term. However, it is a report of follow up data from a randomized controlled study [20], in preterm infants. The infants in that study received 2 doses of 12.5 $\mathrm{mg} / \mathrm{kg}$ of hydrocortisone 12 hours apart, the mean gestational age was about 32 weeks in both groups of infants, therefore did not fit my original criteria for entry into the systematic review, I have therefore performed the metaanalysis both with and without the Fitzhardinge study, and there is no major difference in the results, the graphs include her study, in which there appears to have been no contamination of the randomization schedule by treatment of the controls with steroids. In this study steroid treatment was associated with a substantial increase in intraventricular hemorrhage, a decrease in scores on the Griffiths scales of motor development from 104 to 93, and a possible increase in gross neurological abnormalities. There are probably 3 steroid and 1 control infant with significant motor abnormalities at follow up who could be defined as having CP, but one of the steroid treated infants was not actually seen at 12 months. The numbers of infants who have a developmental quotient more than $2 \mathrm{SD}$ below the mean is not given. I have therefore added the infants with motor dysfunction to the meta-analysis, but I have assumed that there were no other infants with serious developmental delay, and therefore, I have added the same numbers to the neurodevelopmental disability figures also.

The results from Subhedar's study have appeared in a letter to the British Medical Journal. This study was originally a controlled trial of both dexamethasone and nitric oxide inhalation, or both, in a factorial design, which included 42 infants. Infants were enrolled at 96 hours of age if they satisfied criteria for a high risk of bronchopulmonary dysplasia. 22 infants survived, of whom 21 had follow up examinations performed at 30 months corrected age. Cerebral palsy rates were not different between groups, nor were rates of significant developmental delay or severe disability. No details of methodology were included in this letter.

The final study has only been reported as an abstract [21] and reports cerebral palsy rates (age of assessment unclear) of 4/9 steroid treated vs $2 / 8$ control infants from an original study with 10 infants in each group. No data on other developmental outcomes were presented. I have therefore also assumed a total rate of neuro-develop- 


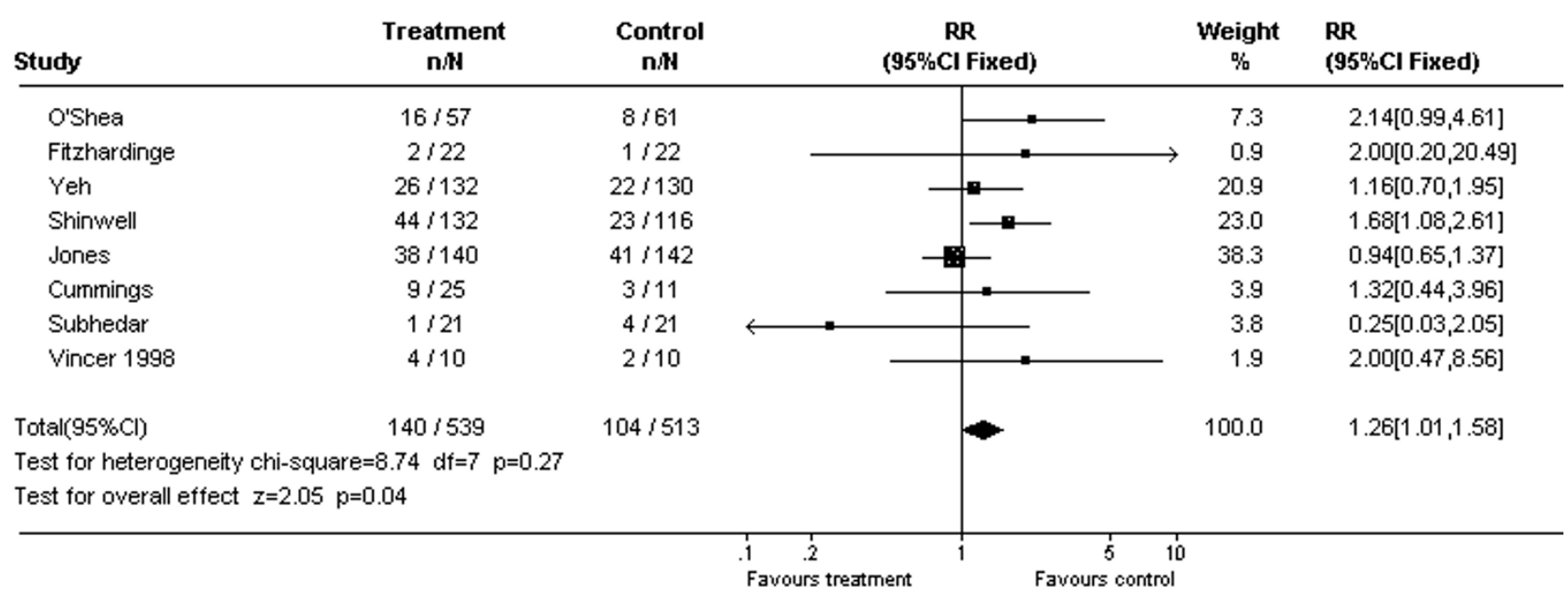

\section{Figure 2}

Meta-analysis of the effects of postnatal steroids on neurodevelopmental impairment, among all randomized infants. Studies are displayed in order of the degree of known contamination of the randomization, Fitzhardinge and O'Shea known to have no contamination, Yeh, Shinwell, and Jones with progressively increasing degrees of contamination, and Cummings, Subhedar and Vincer unknown.

mental impairment of $4 / 9$ and $2 / 8$ followed up infants respectively.

I recognize that the definition of impairment in each of the studies has varied $[10,17,19]$, nevertheless the proportions of babies adversely affected is broadly comparable, and there are some similarities in outcome groupings. For the meta-analysis I have tried as far as possible to apply a definition of neuro-developmental impairment which includes all infants who have an abnormality which appears likely to affect day to day function, this includes a developmental quotient more than 2 standard deviations below the normal mean, a diagnosis of cerebral palsy, and blindness. I recognize that some infants with CP are not severely impaired, and that some infants who do not fall into these groups may actually be severely impaired, but given the limitations of the available data I think this is the optimal approach to determining the incidence of adverse neurological outcomes that would be of interest to families.

\section{Results of the analysis}

The eight studies together randomized 1052 infants, 292 of whom are known to have died, the relative risk of death is not statistically significant in any of the studies, and there is no apparent effect of the extent of contamination on mortality (Figure 1). For 679 of the surviving infants some follow up data are available.

These studies demonstrate a relative risk for neuro-developmental impairment among all randomized infants of 1.26 (95\% CI 1.01, 1.58), which is within the confidence intervals of each of the included studies (Figure 2). The relative risk for neuro-developmental impairment among surviving, followed up, infants overall is 1.34 (95\% CI 1.09, 1.64). In those 4 studies with less than $30 \%$ contamination the RR is 1.66 (95\% CI 1.26, 2.19, figure 3). When only these studies, with less than $30 \%$ contamination are included, the risk difference for neuro-developmental impairment among all randomized infants is 0.09 , for a number needed to harm of 11. That is, for every eleven patients eligible for steroid treatment, eight will survive regardless of whether or not steroids are given, if treated with steroids there will be 1 more surviving infant with neuro-developmental impairment.

The relative risk for the development of cerebral palsy is 1.92 with steroids compared to control among all randomized infants, (95\% confidence intervals 1.41 to 2.61 ). There appears to be a trend in the size of the apparent effect, which decreases as the degree of contamination increases (figure 4). The relative risk for cerebral palsy among surviving, followed up, infants in all the studies is 2.02 (95\% CI 1.51, 2.71 figure 5) In those studies with less than $30 \%$ contamination the relative risk for cerebral palsy is 2.89 (95\% CI 1.96, 4.27), the incidence of cerebral palsy being $78 / 203$ (38\%) in surviving, followed up, treated infants and 28/206 (14\%) in surviving controls, a risk difference of 0.25 . The risk difference among all randomized infants in the studies with less than $30 \%$ contamination is 0.14 , which gives a number needed to harm of 7 . In other words for every 7 patients eligible for ster- 


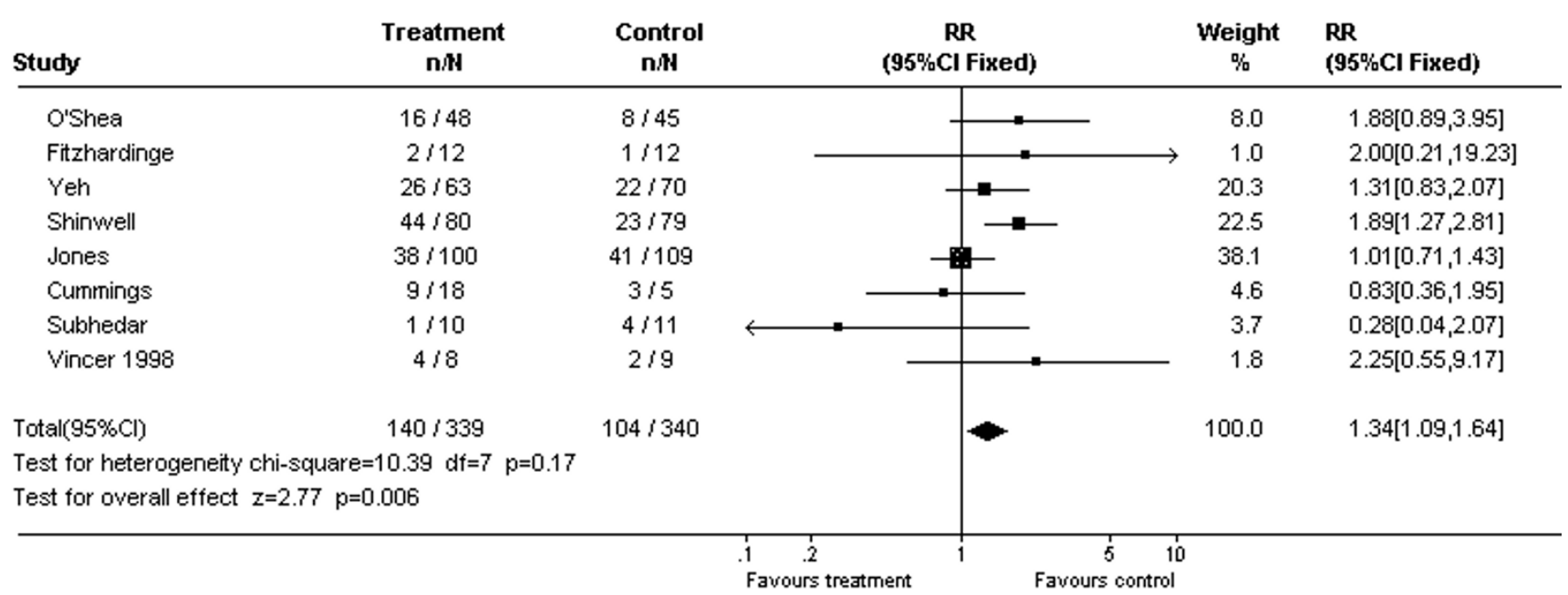

\section{Figure 3}

Meta-analysis of the effects of postnatal steroids on neurodevelopmental impairment among surviving, followed up, infants. Studies are displayed in order of the degree of known contamination of the randomization, Fitzhardinge and O'Shea known to have no contamination, Yeh, Shinwell, and Jones with progressively increasing degrees of contamination, and Cummings, Subhedar and Vincer unknown.

oid treatment 5 will survive regardless of steroid treatment, if administered steroids one more of the surviving infants will develop cerebral palsy.

\section{Discussion}

The analysis herein is limited by the relatively small number of infants who have been adequately assessed in comparison to the huge numbers of children that have been enrolled in more than 40 prospective trials. Furthermore, the unwillingness of the neonatal community to avoid giving control group infants glucocorticoids has substantially impeded the ability to obtain useful follow up information. The contamination of these results by crossed over infants would tend to reduce any difference between the groups, and thus probably reduces the apparent size of the adverse effects that steroids have on the developing brain. The figures, which show a progressive reduction in the size of the apparent effect on cerebral palsy frequency as the extent of contamination increases supports this contention. I have in this analysis lumped together several studies with widely differing timing of steroids and dosage schedules. The relative homogeneity of the results suggests that potent pharmacological doses of steroids at any age and at any dose may not be safe for the brain of the premature infant, even a 3 day course is apparently associated with severely adverse outcomes [18]. The groups of studies included herein do not show any beneficial effect on mortality, nor is there any evidence from the individual studies of long term pulmonary benefit.
It must be admitted that the methodology of the follow up studies varied widely, and in particular that the criteria for the diagnosis of cerebral palsy are often not stated in the publications, despite this many of the studies had blinded assessment of the infants, including the 3 largest studies of the group of 4 which had less than $30 \%$ contamination, and therefore the relative effects are probably reliable, even if the severity of the consequent disability need not necessarily be severe.

Recent data, from 1999, from the Vermont Oxford network shows that among participating institutions (which cover North America, Europe, the Middle East, the Far East and Australasia) approximately 40\% of extremely low birth weight babies receive postnatal steroids. The multi-centre Canadian NICU network provided me with data for 1,085 extremely low birth weight infants who survived to 28 days. By 28 days of life $38 \%$ of them had received postnatal steroids, it is likely that still more infants received steroids after 28 days. When we then estimate the number of babies who have been injured by steroids the over whelming size of this disaster becomes apparent; of 360,000 infants born in Canada each year approximately $1 \%$ are very low birth weight, with probably half of those weighing less than $1000 \mathrm{~g}$, at least forty $\%$ of these infants receive steroids, or 800 infants a year. If the above calculations of "numbers needed to harm" apply generally to this group of infants, then 70 extra infants in Canada every year will have neuro-developmental impairment as a result of postnatal steroid treatment, and 110 extra infants will have cerebral palsy. These esti- 


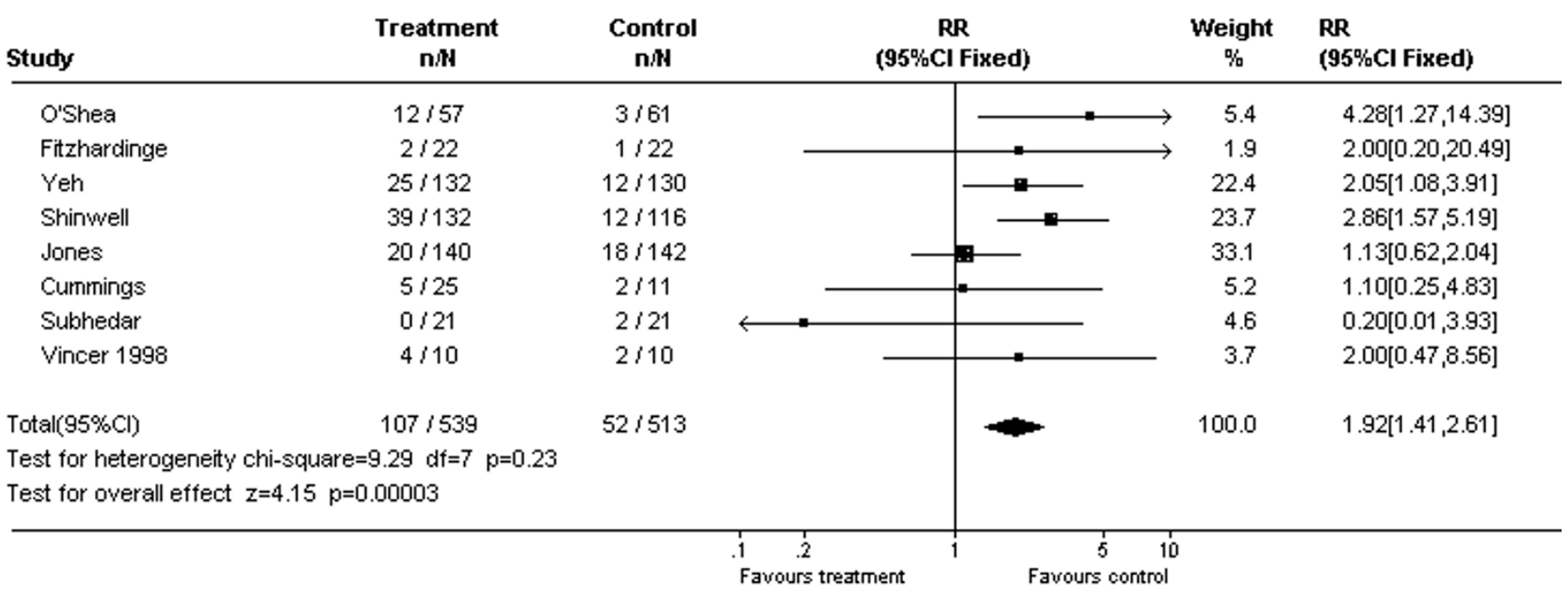

\section{Figure 4}

Meta-analysis of the effects of postnatal steroids on cerebral palsy, among all randomized infants. Studies are displayed in order of the degree of known contamination of the randomization, Fitzhardinge and O'Shea known to have no contamination, Yeh, Shinwell, and Jones with progressively increasing degrees of contamination, and Cummings, Subhedar and Vincer unknown.

mates should be multiplied by approximately 14 to estimate the annual number of affected infants in the USA, i.e. a birth rate of about 3.5 million per year, and a very low birth weight incidence of $1.4 \%$ [22]. These huge numbers are themselves probably an underestimate, as they assume a threshold effect, with a proportion of infants being affected to the extent of developing identifiable neuro-developmental impairment, and the remainder being unaffected. It seems much more likely that impairment of brain growth is a consistent adverse effect; certainly the impairment of somatic growth is very consistent, and therefore the majority of infants receiving postnatal steroids are probably injured to a greater or lesser extent.

This analysis strongly suggests that the single most effective intervention which could currently be introduced for improving neuro-developmental outcomes of extremely low birth weight infants would be to immediately abandon the use of postnatal steroids for chronic lung disease. Abandoning all use of postnatal steroids for this indication would not increase mortality, prolong hospitalisation, or increase the numbers of infants receiving home oxygen therapy. The only adverse effect would probably be an increase in the duration of assisted ventilation, but the financial costs of such an effect are easily dwarfed by the reduced need for rehabilitation services, developmental interventions, special schooling, and emotional pain and suffering. Other interventions to reduce the duration of assisted ventilation, including immediate surfactant administration, post-extubation nasal ventilation, permissive hypercapnia and an attitude which encourages weaning and extubation of even the tiniest of infants will probably mitigate this effect.

Is this effect surprising? Noble-Jamieson, in a small trial in 1989, showed a substantial increase in ultrasound brain abnormalities in dexamethasone treated infants [23] a finding replicated by Shinwell's study [18]. One large multi-centre trial was stopped because of increased complications, which included periventricular leukomalacia [24]. We have known for years that steroid use in premature infants impairs growth, including head growth [25], and that animal models show impaired brain growth and development when exposed to steroids [26]. Caution was urged 23 years ago [26] when antenatal steroids were first being used, which lead to extensive evaluation of the neuro-developmental outcome of infants after antenatal steroid administration and the documentation that adverse outcome was not increased. The uncritical acceptance and use of postnatal steroids by the majority of neonatologists, without any similar adequate evaluation, is yet another object lesson in the need for constant vigilance and scepticism.

The short term benefits of steroids: improved gas exchange, decreased ventilator requirements, and more rapid extubation leading to shortened ventilator duration, are accompanied by an increase in many complications, including gastro-intestinal haemorrhage and perforation, periventricular leukomalacia, hyperglycae- 


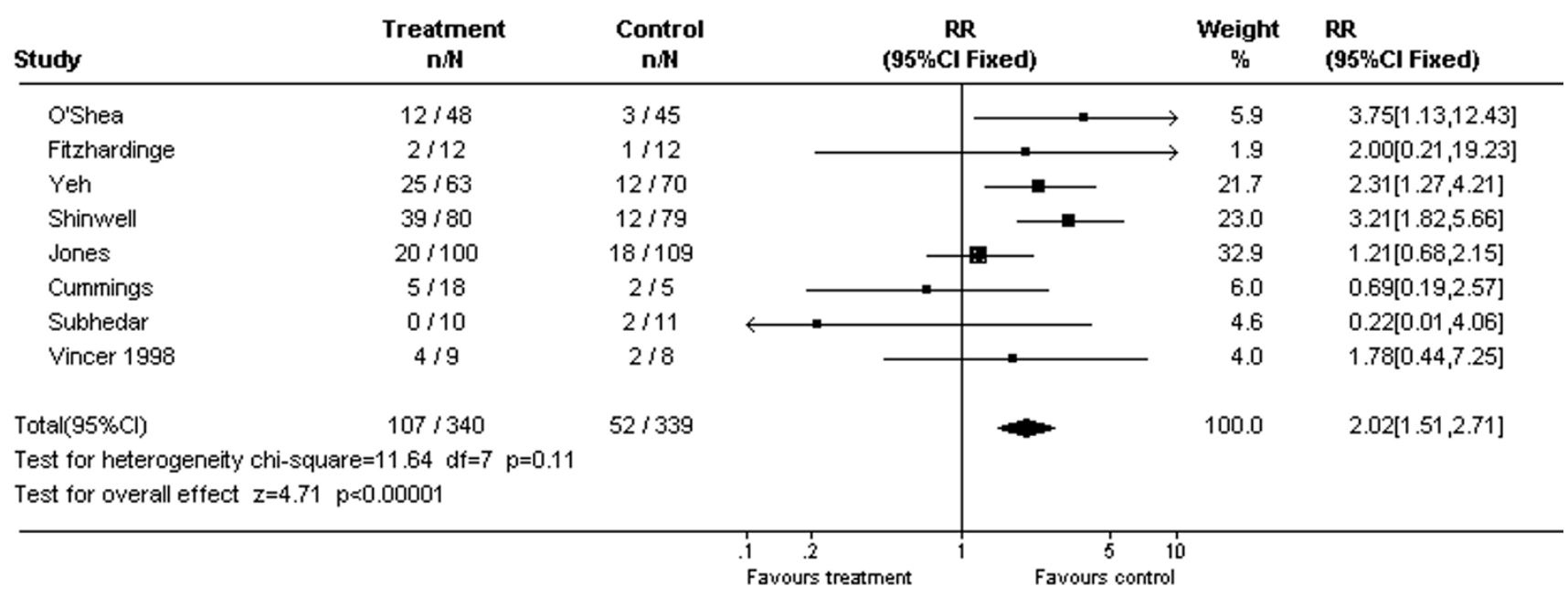

\section{Figure 5}

Meta-analysis of the effects of postnatal steroids on cerebral palsy among surviving, followed up, infants. Studies are displayed in order of the degree of known contamination of the randomization, Fitzhardinge and O'Shea known to have no contamination, Yeh, Shinwell, and Jones with progressively increasing degrees of contamination, and Cummings, Subhedar and Vincer unknown.

mia, hypertension, cardiac hypertrophy, and sepsis. The long term adverse consequences do not seem to be associated with any proven long term benefit.

It could be hypothesized that there may be a much lower dose and shorter course of steroids which has some beneficial effects on lung injury without adverse effects on brain growth, however, such a dose regime has not been defined, and searching for such a regime must only take place within the context of adequately powered prospective randomized controlled trials which have neuro-developmental outcome as the primary outcome variable. It may be that the use of less potent steroids, in doses designed to mimic stress cortisol levels, may have a role to play [27], such doses of steroids exert largely genomic effects, with a markedly different side effect profile, but the same restrictions must be applied to studies investigating these high "physiologic" doses.

There have been calls for a further multicentre randomized controlled trial to try and finally answer the question of the risk benefit ratio of steroids. There are already some 42 randomized controlled trials in the literature, and despite that there is no clear long term benefit from systemic pharmacologic doses of steroids. If infants are not more likely to survive then I believe that few parents will be willing to face the increased risk of neurological damage. It seems to me to be highly unlikely that a further trial will finally discover a benefit of sufficient magnitude to outweigh the hazards which are presented in this paper.
The introduction of some technologies and treatments specific to the newborn, such as surfactant and to some extent nitric oxide, have been models of the scientific practice of medicine with large, adequately powered, prospective randomized controlled trials being performed in sufficient numbers prior to the widespread use of the treatments. These advances have been proven efficacious, with clinically important endpoints, endpoints in which parents and babies are interested, being clearly improved by the treatments (survival, reducing the need for ECMO), and adequate evaluation of long-term outcomes having been undertaken. In contrast the uncritical application of many treatments, of dubious efficacy and uncertain long-term effects, continues. This is particularly true to the extrapolation of data from adults or off label use of medications that have never been investigated for newborns.

The one common thread in all of the neonatal disasters outlined above is the uncritical introduction of therapies without adequate evaluation. Future and continuing improvements in neonatal outcomes and avoidance of future disasters will only occur if we make a concerted effort to improve the reliability, applicability and usefulness of the evidence which is available, to propagate that evidence and practice according to it.

\section{References}

I. Silverman WA, Flynn JT: Overview: a developmental retinopathy reconsidered. In Silverman WA, Flynn JT, Eds, Retinopathy of Prematurity, Blackwell Scientific Publications, Boston, 1985, 
2. McDonald AS: Neurological and ophthalmic disorders in children of very low birth weight. Br Med J 1962, I:895-900

3. Feder HM Jr, Osier C, Maderazo EG: Chloramphenicol: A review of its use in clinical practice. Rev Infect Dis |98I, 3:479-49|

4. Menon PA, Thach BT, Smith CH, Landt M, Roberts JL, Hillman RE, Hillman LS: Benzyl alcohol toxicity in a neonatal intensive care unit. Incidence, symptomatology, and mortality. Am J Perinatol 1984, 1:288-292

5. Anderson JM, Cockburn F, Forfar JO, Harkness RA, Kelly RW, Kilshaw B: Neonatal spongioform myelinopathy after restricted application of hexachlorophane skin disinfectant. J Clin Pathol 1981, 34:25-29

6. Barrington KJ, Finer NN: An evaluation of the efficacy of dexamethasone in early bronchopulmonary dysplasia. J Perinatol 1985, 5:26-32

7. Barrington KJ, Finer NN: Treatment of bronchopulmonary dysplasia. A review. Clin Perinatol 1998, 25:177-202

8. Halliday HL, Ehrenkrantz RA: Moderately early (7- 14 ) days postnatal corticosteroids for preventing lung disease in preterm infants (Cochrane Review). In: the Cochrane Library, Issue I, 200 I. Oxford: Update Software.

9. Doyle L, Davis P: Review article: postnatal corticosteroids in preterm infants: systematic review of effects on mortality and motor function. J Paediatr Child Health 2000, 36. 36(2. 2): I0I107

10. O'Shea TM, Kothadia JM, Klinepeter KL, Goldstein DJ, Jackson BG, Weaver RG 3rd, Dillard RG: Randomized placebo-controlled trial of a 42-day tapering course of dexamethasone to reduce the duration of ventilator dependency in very low birth weight infants: outcome of study participants at I-year adjusted age. Pediatrics 1999, 104:15-21

II. Jones R, Wincott E, Elbourne D, Grant A: Controlled trial of dexamethasone in neonatal chronic lung disease: a 3-year follow-up. Pediatrics 1995, 96:897-906

12. Avery GB, Fletcher AB, Kaplan M, Brudno DS: Controlled trial of dexamethasone in respirator-dependent infants with bronchopulmonary dysplasia. Pediatrics 1985, 75:106-III

13. Shinwell ES, Karplus M, Reich D, Weintraub Z, Blazer S, Bader D, Yurman S, Dolfin T, Kogan A, Dollberg S, et al: Early postnatal dexamethasone treatment and increased incidence of cerebral palsy. Arch Dis Child Fetal Neonatal Ed 2000, 83:FI77-18I

14. Fitzhardinge PM, Eisen A, Leitenyi C, metrakos K, Ramsay M: Equelae of early steroid administration to the newborn infant. Pediatr 1974, 53:877-883

15. Subhedar NV, Bennett AJ, Wardle SP, Shaw NJ: More trials on early treatment with corticosteroids are needed. BMJ 2000, 320:94I-

16. Yeh TF, Lin YJ, Hsieh WS, Lin HC, Lin CH, Chen JY, Kao HA, Chien $\mathrm{CH}$ : Early postnatal dexamethasone therapy for the prevention of chronic lung disease in preterm infants with respiratory distress syndrome: A multicenter clinical trial. Pediatrics 1997, 100:E3-

17. Yeh TF, Lin YJ, Huang CC, Chen YJ, Lin CH, Lin HC, Hsieh WS, Lien YJ: Early dexamethasone therapy in preterm infants: a follow up study. Pediatr 1998, I0I:E7-

18. Shinwell ES, Karplus M, Zmora E, Reich D, Rothschild A, Blazer S, Bader D, Yurman S, Dolfin T, Kuint J, et al: Failure of early postnatal dexamethasone to prevent chronic lung disease in infants with respiratory distress syndrome. Arch Dis Child Fetal Neonatal Ed 1996, 74:F33-37

19. Cummings ||, D'Eugenio DB, Gross SJ: A Controlled Trial of Dexamethasone in Preterm Infants at High Risk for Bronchopulmonary Dysplasia. N Engl] Med 1989, 320:1505-1510

20. Baden M, Bauer CR, Colle E, Klein G, Taeusch HW, Stern L: A controlled trial of hydrocortisone therapy in infants with respiratory distress syndrome. Pediatr 1972, 50:526-534

21. Vincer MJ, Allen AC: Double blind controlled trial of 6-day pulse of dexamethasone for very low birth weight infants (VLBW $<1500$ grams) who ventilator dependent at 4 weeks of age. Pediatr Res 1998, 43:20IA-

22. Guyer B, Hoyert DL, Martin JA, Ventura SJ, MacDorman MF, Strobino DM: Annual summary of vital statistics. 1998. Pediatrics 1999, I 04:1229-1246

23. Noble-Jamieson CM, Regev R, Silverman M: Dexamethasone in neonatal chronic lung disease: pulmonary effects and intracranial complications. Eur J Pediatr 1989, 148:365-367
24. Soll RF: Early Postnatal Dexamethasone Therapy for the Prevention of Chronic Lung Disease. Pediatr Res 1999, 45:226A-

25. Weiler HA, Paes B, Shah JK, Atkinson SA.: Longitudinal assessment of growth and bone mineral accretion in prematurely born infants treated for chronic lung disease with dexamethasone. Early Hum Dev 1997, 47(3):27I-286

26. Weichsel ME Jr.: The therapeutic use of glucocorticoid hormones in the perinatal period: potential neurological hazards. Ann Neurol 1977, 2:364-366

27. Watterberg KL, Gerdes JS, Gifford KL, Lin HM: Prophylaxis against early adrenal insufficiency to prevent chronic lung disease in premature infants. Pediatrics 1999, 104: 1258-1263

\section{Pre-publication history}

The pre-publication history for this paper can be accessed here:

http://www.biomedcentral.com/content/backmatter/ 1471-2431-1-1-b1.pdf

Publish with BioMedcentral and every scientist can read your work free of charge

"BioMedcentral will be the most significant development for disseminating the results of biomedical research in our lifetime." Paul Nurse, Director-General, Imperial Cancer Research Fund

Publish with BMc and your research papers will be:

- available free of charge to the entire biomedical community

- peer reviewed and published immediately upon acceptance

- cited in PubMed and archived on PubMed Central

- yours - you keep the copyright

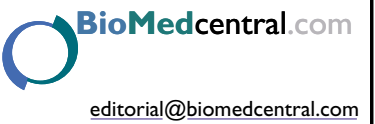

